\title{
Smoking-Related Interstitial Lung Disease
}

Lars Hagmeyer, Winfried Randerath

\section{SUMMARY}

Background: Smoking-related interstitial lung diseases (SR-ILDs) are a heterogeneous group of diseases with major clinical significance. Reliable epidemiological data are not yet available.

Method: Review of pertinent literature retrieved by a selective search in PubMed.

Results: The available data on many aspects of SR-ILDs are sparse, but recent studies on the pathophysiology and targeted treatment of these conditions have revealed ways in which clinical outcomes can be improved. Highresolution computerized tomography should be used for differential diagnosis; lung biopsy is often unnecessary. Oncogenic mutations play a role in the pathogenesis of pulmonary Langerhans-cell histiocytosis (PLCH). In the future, cladribine and vemurafenib may be treatment options for PLCH. Desquamative interstitial pneumonia (DIP) may be difficult to distinguish from respiratorybronchiolitis-associated interstitial lung disease (RB-ILD); DIP is treated with steroids and sometimes with immune suppressants. In idiopathic pulmonary fibrosis (IPF), the antifibrotic drugs pirfenidone and nintedanib can delay disease progression. Smoking is also a risk factor for combined pulmonary fibrosis and emphysema (CPFE), rheumatoid-arthritis-associated interstitial lung disease (RA-ILD), pulmonary alveolar proteinosis (PAP), acute eosinophilic pneumonia (AEP), and diffuse alveolar hemorrhage (DAH) in Goodpasture syndrome.

Conclusion: In smokers with exertional dyspnea and/or a nonproductive cough, SR-ILDs must be considered in the differential diagnosis. If an SR-ILD is suspected, the patient should be referred to a pulmonary specialist. Early treatment and smoking cessation can improve clinical outcomes, particularly in the acute and chronically progressive types of SR-ILD.

\section{- Cite this as:}

Hagmeyer L, Randerath W: Smoking-related interstitial lung disease.

Dtsch Arztebl Int 2015; 112: 43-50. D0I: 10.3238/arztebl.2015.0043 nhalation of tobacco smoke is a risk factor for various diseases of the lungs and respiratory tract. Besides chronic obstructive pulmonary disease, pulmonary emphysema, and lung cancer, this group of diseases includes smoking-related interstitial lung disease (SR-ILD).

The term "interstitial lung disease" (ILD) is used for a category of diseases characterized by damage to the pulmonary interstitial tissue (sometimes involving alveolar epithelium and pulmonary blood and lymph vessels). Smoking is a risk factor for the development and unfavorable course of a number of $\operatorname{ILD}(1,2)$. Conventionally, "smoking-related interstitial lung disease" embraces the entities known to have a strong epidemiological association with smoking:

- Pulmonary Langerhans cell histiocytosis (PLCH)

- Respiratory-bronchiolitis - associated interstitial lung disease (RB-ILD)

- Desquamative interstitial pneumonia (DIP) (e1)

However, smoking may also be a risk factor for other ILD:

- Idiopathic pulmonary fibrosis (IPF)

- Combined pulmonary fibrosis and emphysema (CPFE)

- Acute eosinophilic pneumonia (AEP)

- Rheumatoid-arthritis - associated interstitial lung disease (RA-ILD)

- Diffuse alveolar hemorrhage (DAH) in Goodpasture syndrome

- Pulmonary alveolar proteinosis (PAP) (2-5, e2).

The group of SR-ILD are among the less common pulmonary diseases, with no reliable data on incidence and prevalence. Despite their rarity, these diseases are of great importance for the medical care of smokers who present with dry cough and/or exercise-induced dyspnea. Diagnostic and therapeutic nihilism on the part of patients with SR-ILD is no longer justified, for several reasons: First, there are new specific treatment options for various SR-ILD entities. Second, if the prognosis is poor the indications for lung transplantation should be determined early. Finally, particularly in acute forms of ILD (AEP, DAH in Goodpasture syndrome), the prognosis will be improved if the specific treatment is accompanied by the patient giving up smoking.

Apart from clinical examination and determination of lung function, the most important instrument in the diagnosis of ILD is high-resolution computer tomography. Bronchoalveolar lavage can also yield valuable additional information. Surgical lung biopsy is seldom necessary. The Table lists the distinctive 


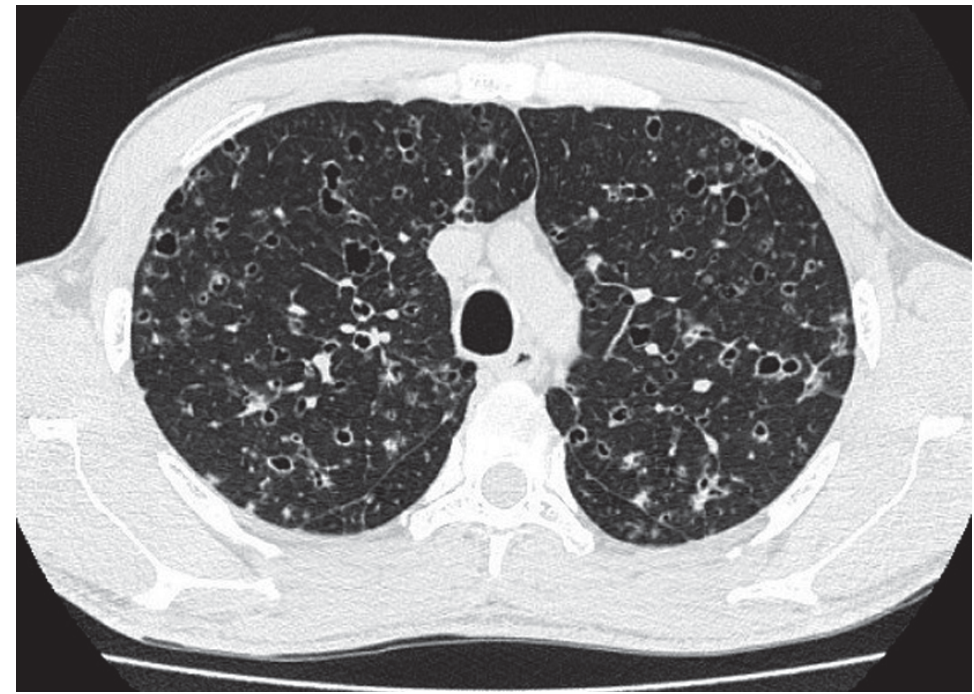

Figure 1: High-resolution computer tomography in pulmonary Langerhans cell histiocytosis. Late stage with irregular cystic formations

features of the entities PLCH, RB-ILD, DIP, IPF, and CPFE as identified in a selective survey of the literature (PubMed). Our understanding of SR-ILD has grown in recent years. New insights into the pathophysiology of various entities of SR-ILD have paved the way for specific treatments.

\section{Pulmonary Langerhans cell histiocytosis}

More than $98 \%$ of patients who develop PLCH are active or former smokers (e3). In contrast to other forms of histiocytosis, smoking seems to represent the central trigger for the disease $(6,7)$. Exposure to tobacco smoke results in proliferation of the Langerhans cells as seen in lung tissue samples and bronchoalveolar lavage fluid (e4). Oncogenic mutations of the BRAF-V600E gene have recently been demonstrated in the pulmonary lesions, speaking for underlying clonal proliferation (8).

\section{Treatment and prognosis}

Overall the prognosis of PLCH is good. If the patient stops smoking at an early stage, reversal of the pulmonary changes may ensue (eFigure) (e5). In advanced stages, however (Figure 1), a progressive disease course may become apparent; pulmonary hypertension is observed in $>75 \%$ of symptomatic patients (e6, e7). Systemic corticosteroids may be a treatment option in patients with significant impairment, and if the disease continues to progress immunosuppressants and cytostatics can be used. However, the evidence for these approaches is confined predominantly to retrospective analyses of small case series (e8, e9). Interestingly, early case reports $(9, \mathrm{e} 10)$ describe a positive effect for treatment with cladribine (2-chlorodeoxyadenosine, 2-CdA), a purine analog that induces apoptosis in lymphocytes and monocytes and thus exerts a cytostatic and immunosuppressant effect (e11). To date, however, there are no prospective studies on the treatment of PLCH with cladribine. In cases of systemic histiocytosis a treatment response has been shown for the substance vemurafenib, a BRAF kinase inhibitor, in the presence of an oncogenic mutation of the BRAF-V600E gene (10). It remains to be investigated whether vemurafenib is also suitable for the treatment of patients with PLCH who display this mutation.

Lung transplantation may be indicated in patients with treatment-resistant disease. Recurrence of PLCH may occasionally be found (e12).

\section{Respiratory bronchiolitis-associated interstitial lung disease}

Respiratory bronchiolitis is an expression of the chronic inflammatory response to inhalation of tobacco smoke and can be demonstrated in all smokers (e13, e14). The recovery time after cessation of smoking ranges from 1 to 30 years (e14). The respiratory bronchiolitis itself seldom becomes symptomatic.

If the changes are sufficiently pronounced to be discernible on diagnostic imaging, then the respiratory bronchiolitis is accompanied by interstitial lung disease, which may become symptomatic (Figure 2) (11). A patient with RB-ILD usually has a smoking history of over 30 pack-years.

\section{Treatment and prognosis}

Beyond giving up smoking, no specific treatment is required, because the prognosis is very good. The disease typically has a stable course and patients who stop smoking may show a tendency towards recovery (e15). No severely progressive or fatal cases of RB-ILD have been described in the literature (e15). Small retrospective observational studies have shown occasional cases of improvement with steroids, but treatment should be considered only in the presence of significant functional impairment (11).

\section{Desquamative interstitial pneumonia}

Desquamative interstitial pneumonia is related to smoking in over $90 \%$ of cases (Figure 3). Forms of DIP associated with other external noxae, autoimmune disease, infection, or drug intake are much rarer (12, e16-e19). Some characteristics of smoking-related DIP are reminiscent of RB-ILD; clear differentiation may be difficult. Nevertheless, the observed differences in disease course and prognosis preclude the understanding of RB-ILD and DIP as different stages or degrees of severity of the same disease.

DIP in childhood is not associated with tobacco smoke. The reader is referred to the relevant literature (e20).

\section{Treatment and prognosis}

Untreated, around two thirds of patients with DIP show disease progression; however, spontaneous improvement has also been described (12).

The mortality of DIP ranges from around 6 to $28 \%$ $(12,13)$. The patient should be strongly advised to stop 


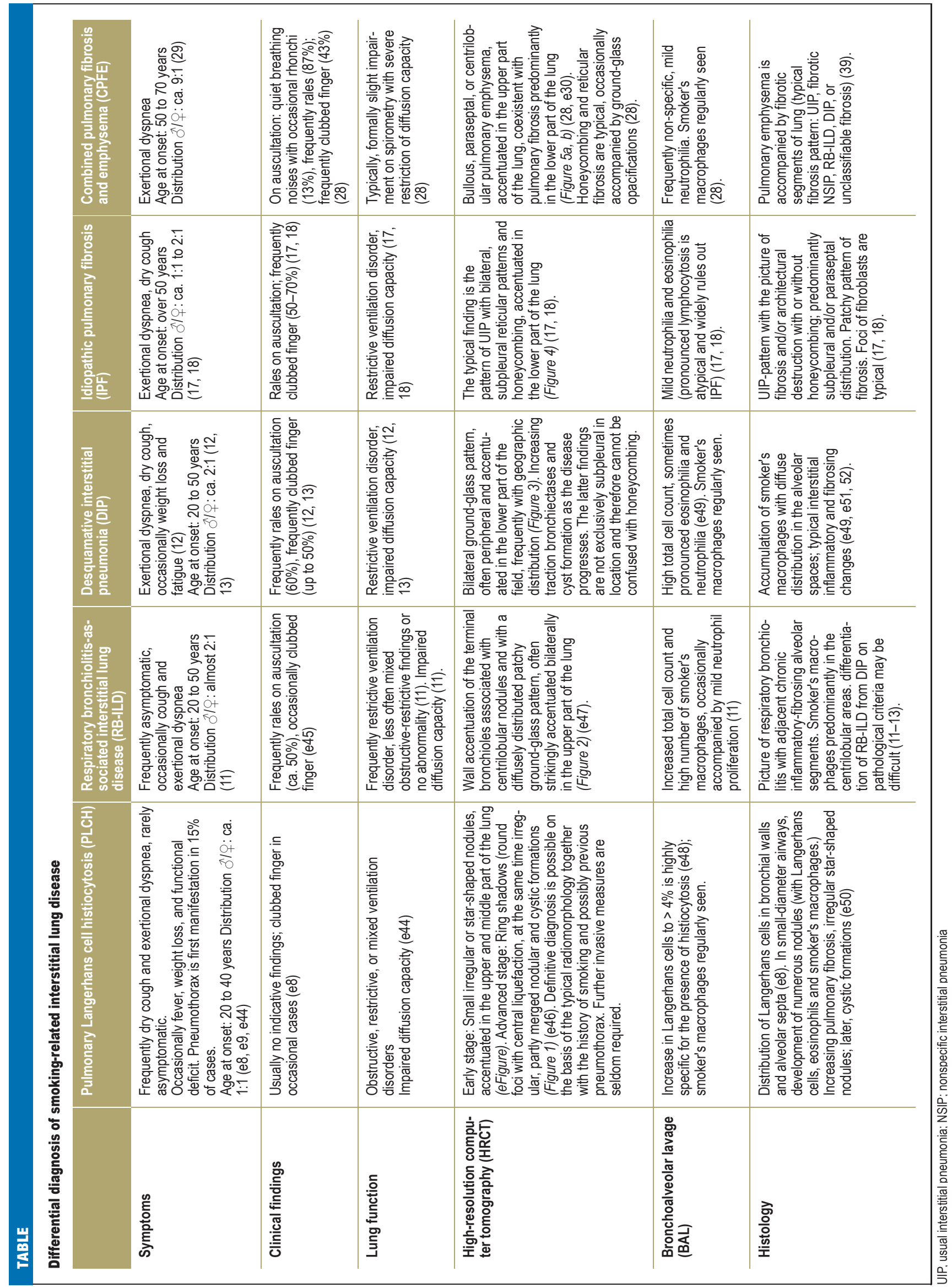




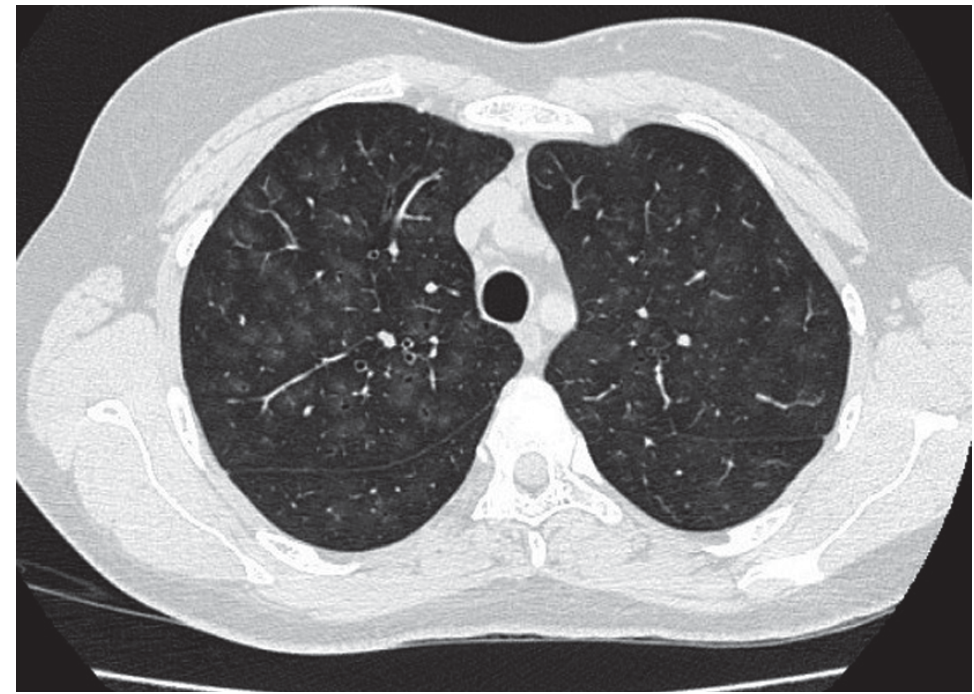

Figure 2: High-resolution computer tomography in respiratory bronchiolitis-associated interstitial lung disease. Bronchiolocentric interstitial ground-glass opacifications, accentuated in the upper part of the lung.

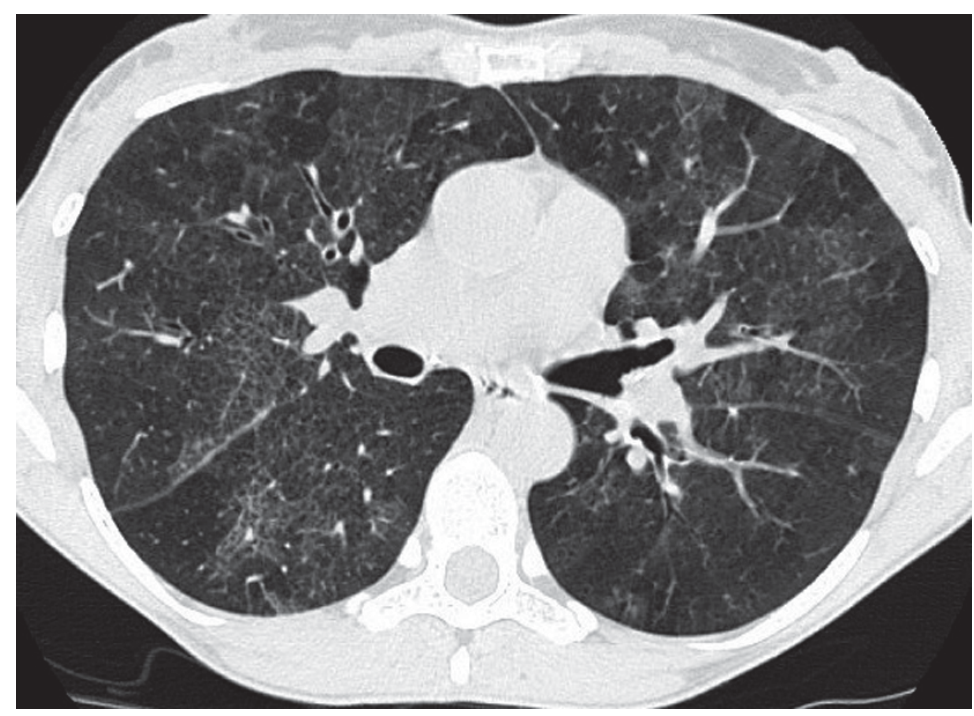

Figure 3: High-resolution computer tomography in desquamative interstitial pneumonia. Increased interstitial ground-glass and partly reticular patterns with geographical distribution smoking. Administration of systemic corticosteroids usually achieves stabilization, rarely improvement 12 , e21). In the case of long-term treatment, reduction of steroid consumption by combination with cyclophosphamide or azathioprine can be considered. Overall, however, the evidence on the effect of drug treatment for DIP is scanty and based essentially on retrospective observational studies and case reports (12, e21, e22). Provided all the criteria are fulfilled, lung transplantation may represent an option. One case report describes recurrent DIP in the transplanted organ after single-lung transplantation (14).

\section{Idiopathic pulmonary fibrosis}

Idiopathic pulmonary fibrosis does not occur preferentially in smokers and is therefore not, strictly speaking, one of the SR-ILD. Overall, however, active or former smokers have a 1.6 times greater risk of developing IPF than non-smokers $(15,16)$. The prevalence of IPF is around 2 to 43 per 100000 persons; predominantly older adults are affected (e23).

IPF is defined as a particular form of chronic, progressive fibrosing interstitial pneumonia of unknown origin. It is confined to the lung and is associated with the histopathological and/or radiological pattern of "usual interstitial pneumonia" (UIP) (Figure 4) (17, 18). IPF is thus a diagnosis of exclusion, because the UIP pattern can also be present in other ILD (pulmonary asbestosis, chronic exogenic-allergic alveolitis, and ILD triggered by medications or associated with an underlying rheumatological disease).

The mechanism of IPF is unknown. The current opinion is that damage to the alveolar epithelium leads to primary fibrotic remodeling processes. Besides tobacco smoke, many other inhaled noxae have been described as risk factors for the development of IPF (e.g., metal or wood particles, stone dust, particles of vegetable or animal origin) $(17,18)$. Not all cases of IPF are sporadic; rare familiar forms have also been described (e24, e25).

High-resolution computer tomography occupies a central position in the diagnostic algorithm. Histology (surgical biopsy) is considered only if the previous findings are incongruent. The diagnosis should be determined by an interdisciplinary team (pneumology, radiology, pathology) $(17,18)$.

\section{Treatment and prognosis}

On the whole the prognosis of IPF is unfavorable; however, the disease course can differ considerably from patient to patient depending on various risk factors (17). In a retrospective multicenter study the 1-year mortality ranged from $6 \%$ to $39 \%$, depending on the risk profile, and the 3 -year mortality lay between $16 \%$ and $77 \%(19)$.

Lung transplantation is the sole curative treatment for IPF. The results of all studied drug treatments have been disappointing. The IFIGENIA study, published in 2005 , indicated a positive treatment effect for highdose N-acetylcysteine (NAC) (20). The recent 
PANTHER study demonstrated no such effect for NAC monotherapy, however, and so-called triple therapy (prednisolone, azathioprine, NAC) was associated with increased mortality (21).

In 2011 the antifibrotic substance pirfenidone was licensed as the first specific drug for treatment of mild and moderate IPF in Europe. According to the results of the CAPACITY and ASCEND studies, pirfenidone can slow the progress of the disease $(22,23)$. The recently published ASCEND study showed a significant treatment effect with regard to the outcome "decline in forced vital capacity (FVC) $\geq 10 \%$ or death" (pirfenidone $16.5 \%$ vs placebo $31.8 \%$ ) (23). The pooled study data (CAPACITY and ASCEND) showed a significant reduction in mortality (pirfenidone $3.5 \%$, placebo $6.7 \%$ ). The most adverse effects of pirfenidone treatment are found particularly in the gastrointestinal tract (nausea $32.8 \%$, dyspepsia $16.8 \%$, diarrhea $21.7 \%$ ) and the skin (rash $28.7 \%$, photosensitivity reaction $12.2 \%$ ). (22).

The studies INPULSIS-1 and INPULSIS-2 showed that the progress of IPF was slowed significantly by treatment with the multikinase inhibitor nintedanib (rate of decline in FVC $\leq 10 \%$ with nintedanib $70.1 \%$, with placebo $60.5 \%$ ) (24). Moreover, fewer patients suffered an acute exacerbation of IPF (nintedanib 1.9\%, placebo $5.6 \%$ after central case review). The observed adverse effects mainly involved the gastrointestinal tract (diarrhea: INPULSIS-1 61.5\%, INPULSIS-2 $63.2 \%$; nausea: INPULSIS-1 $22.7 \%$, INPULSIS-2 $26.1 \%$ ); however, treatment was discontinued due to diarrhea in $<5 \%$ of cases. Nintedanib has recently been licensed in the USA, and approval in Europe is under review. Further new substances for the treatment of IPF are currently under investigation (e26).

Acute exacerbations have particular significance for the prognosis of IPF. Acute exacerbation is defined as rapid deterioration of unknown cause in which the progression of the disease, normally slow and steady, suddenly accelerates, possibly to the point of acute respiratory distress syndrome (ARDS). The 1-year and 3 -year rates of incidence for acute exacerbation of IPF are $14 \%$ and $21 \%(25)$. The probability of death in the acute phase is $>50 \%$, rising to 90 to $100 \%$ in cases where ventilation becomes necessary (e27). Bolus treatment with high-dose intravenous steroids can be tried $(17,18)$.

Further factors relevant to the prognosis are development of pulmonary hypertension and occurrence of lung cancer (4 to $20 \%$ of all patients with IPF) (26). Recent studies have identified gastroesophageal reflux as a risk factor for an unfavorable course of IPF (27, e28); however, the effect of antacid treatment has to be investigated in further prospective studies.

\section{Combined pulmonary fibrosis and emphysema}

Combined pulmonary fibrosis and emphysema probably cannot be viewed as an independent disease entity. Rather, it is a syndrome resulting from simultaneous occurrence of pulmonary fibrosis and pulmonary emphysema, two diseases whose prevalence is elevated

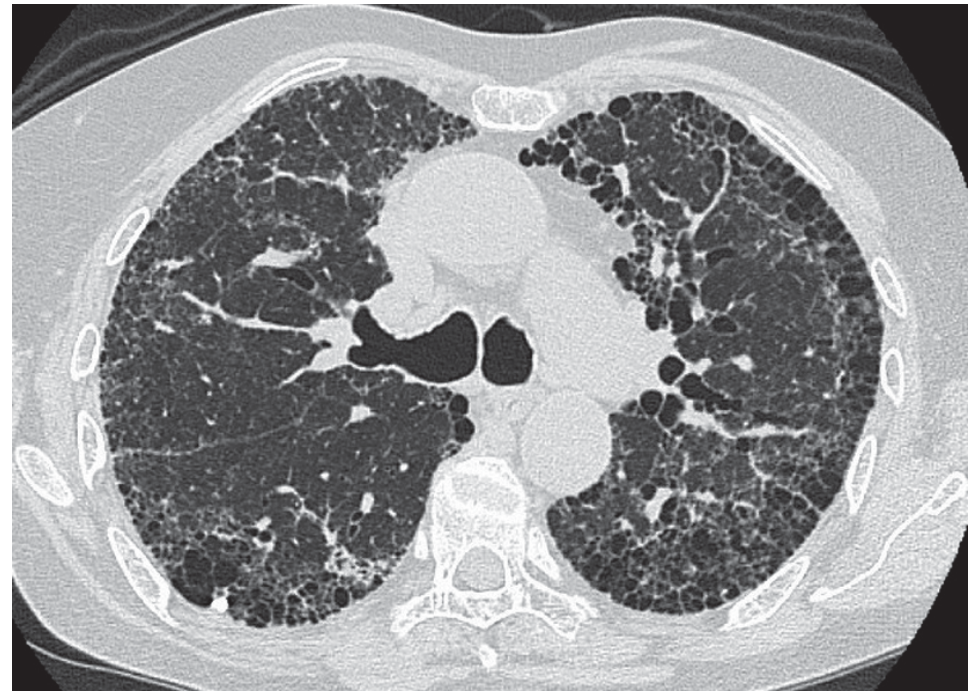

Figure 4: High-resolution computer tomography in idiopathic pulmonary fibrosis. Predominantly basal and subpleural reticular fibrosis with honeycombing

in smokers (28). Nevertheless, the two diseases in combination show typical characteristics that justify separate consideration of patients with CPFE (Figure 5) (e29). Almost exclusively active and former smokers are affected (98\%) (29). With regard to lung function, spirometry is broadly normal but gas exchange is severely impaired (28). High-resolution computer tomography is the principal diagnostic modality. Harvesting of tissue for histology is rarely necessary and can be hazardous in advanced CPFE.

\section{Treatment and prognosis}

There is no specific treatment for CPFE. In analogy to the treatment of patients with either pulmonary emphysema or pulmonary fibrosis alone, the patient should stop smoking, the indication for long-term oxygen treatment should be assessed, and suitable patients should be listed for lung transplantation (29).

The prognosis of patients with CPFE is comparable to that of patients with IPF alone (e30, e31). The prognosis cannot be adequately estimated from the development of lung function parameters. Above all the prognosis is determined by pulmonary hypertension, which occurs in $47 \%$ of patients with CPFE and is associated with 1 -year mortality of $60 \%(28$, e 32$)$.

\section{Other ILD with high prevalence in smokers Acute eosinophilic pneumonia}

Inhalation of tobacco smoke can trigger AEP. The disease can arise both in new smokers and in those who resume smoking after a period of abstinence or increase their consumption $(5,30,31)$. Manifestations have also been described after combined smoking of tobacco and marijuana or cannabis (e33). No robust data on the incidence of AEP are available. A retrospective study in US military personnel found an incidence of 9.1 per 100000 person-years (31). The response to systemic 

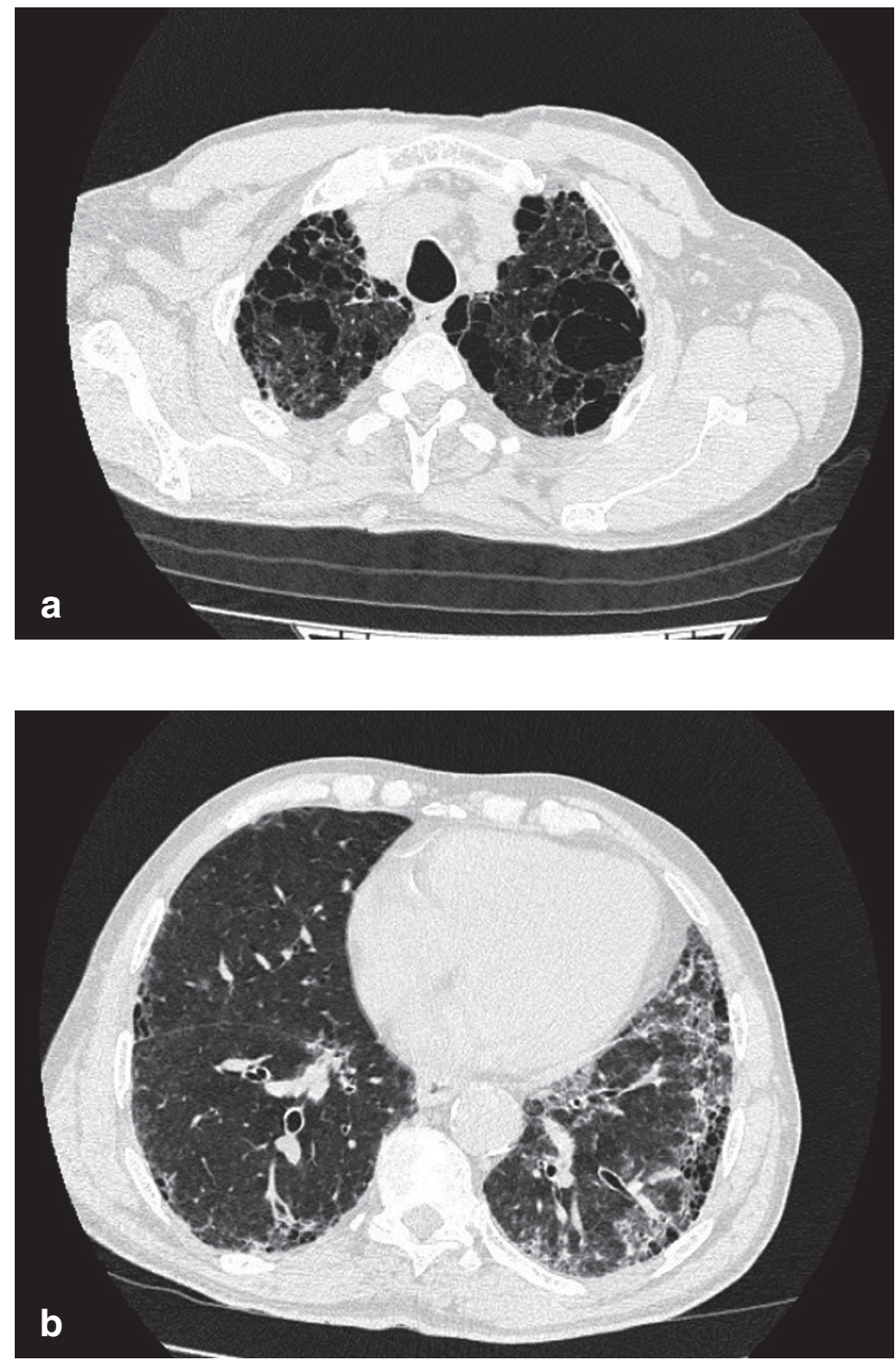

Figure 5: High-resolution computer tomography in combined pulmonary fibrosis and emphysema.

a) Pulmonary emphysema, accentuated in the upper part of the lung

b) Predominantly basal and subpleural fibrosis with largely reticular and less pronounced ground-glass components. patient's rheumatologist. For details of the treatment concept the reader is referred to the relevant literature (e35-e37).

\section{Diffuse alveolar hemorrhage in Goodpasture syndrome}

A case series of 51 patients with glomerulonephritis and anti-glomerular basal membrane antibodies showed a clear association (100\%) between smoking status and the likelihood of the occurrence of DAH (4). Inhalation of tobacco smoke must therefore be viewed as a risk factor for the occurrence of DAH in Goodpasture syndrome. The acute treatment must be managed by an interdisciplinary team. The options for treatment comprise medicinal immune suppression, plasmapheresis, and, in the presence of renal failure, hemodialysis $(33, \mathrm{e} 38)$.

\section{Alveolar proteinosis}

The estimated prevalence of PAP is 0.1 per 100000 persons. The proportion of active or former smokers among patients with PAP is 56 to $79 \%(34, \mathrm{e} 2)$. In the presence of significant impairment of lung function the treatment of choice is whole-lung lavage (e39, e40). If there is no satisfactory response to treatment and anti-GM-CSF antibodies are demonstrated (GM-CSF = granulocyte-macrophage colony-stimulating factor), the patient's suitability for inhalation therapy with GMCSF can be assessed (35).

\section{Smoking-related interstitial lung disease: general treatment principles \\ Smoking cessation}

From the pathophysiological viewpoint, stopping smoking is plausible and advisable in all of the abovementioned diseases. Several case series on individual entities of SR-ILD have reported improvement following cessation of smoking (12, e5, e14, e15).There are no robust data, however, on how the prognosis changes in patients who have given up smoking. DAH in Goodpasture syndrome and AEP are acute conditions that require immediate specific treatment. Both of these diseases have also been reported in patients who have stopped smoking but then started again, reinforcing the importance of smoking cessation $(4,5)$.

\section{Rehabilitation}

Pneumological rehabilitation is particularly important for the preservation of quality of life and functional capacity in patients with chronic progressive disease (36, e41, e42).

\section{Oxygen treatment}

In the presence of significant hypoxia long-term oxygen treatment is indicated and should be prescribed according to the current guidelines (37).

\section{Transplantation}

Patients under 65 with refractory progressive disease and without contraindications can be considered for lung transplantation listing, particularly in the presence 


\section{KEY MESSAGES}

- The possible presence of smoking-related interstitial lung disease must be considered in patients with a positive smoking history and unspecific respiratory symptoms (dyspnea, dry cough).

- Measures for diagnosis and treatment must be planned in cooperation with a pneumologist; if required, a tertiary pulmonary clinical department can also be consulted.

- The most important diagnostic tool is high-resolution computer tomography. There is often no need to obtain a tissue sample for histology.

- The availability of novel treatment options necessitates early establishment of the definitive diagnosis.

- Cessation of smoking may have an immediate positive effect on the prognosis.

- In progressive disease, listing for lung transplantation must be considered in good time.

of a high lung allocation score (LAS), a rapid decline in forced vital capacity of $>10 \%$ within 6 months, requirement for oxygen, and decreased oxygen saturation on exercise (oxygen saturation < 89\%) $(38$, e43). Patients considered suitable for transplantation should be assigned to a specific transplantation center at an early stage.

\section{Conflict of interest statement}

Dr Hagmeyer has received consulting and speaking honoraria from Intermune and Boehringer.

The authors declare that Intermune is funding a study that is being conducted at the scientific institute of Bethanien Hospital.

Manuscript received on 25 March 2014, revised version accepted on 20 0ctober 2014

Translated from the original German by David Roseveare.

\section{REFERENCES}

1. American Thoracic Society, European Respiratory Society: American Thoracic Society/European Respiratory Society International: Multidisciplinary consensus classification of the idiopathic interstitial pneumonias. This joint statement of the American Thoracic Society (ATS), and the European Respiratory Society (ERS) was adopted by the ATS board of directors, June 2001 and by the ERS Executive Committee, June 2001. Am J Respir Crit Care Med 2002; 165: 277-304.

2. Travis WD, Costabel U, Hansell DM, et al.: An official American Thoracic Society/European Respiratory Society statement: Update of the international multidisciplinary classification of the idiopathic interstitial pneumonias. Am J Respir Crit Care Med 2013; 188 733-48.

3. Mikuls TR, Sayles H, Yu F, et al.: Associations of cigarette smoking with rheumatoid arthritis in African Americans. Arthritis Rheum 2010; 62: 3560-8.

4. Donaghy M, Rees AJ: Cigarette smoking and lung haemorrhage in glomerulonephritis caused by autoantibodies to glomerular basement membrane. Lancet 1983; 2: 1390-3.
5. Uchiyama H, Suda T, Nakamura Y, et al.: Alterations in smoking habits are associated with acute eosinophilic pneumonia. Chest 2008 133: 1174-80.

6. Yousem SA, Colby TV, Chen YY, Chen WG, Weiss LM: Pulmonary Langerhans' cell histiocytosis: molecular analysis of clonality. Am J Surg Pathol 2001; 25: 630-6.

7. Favara BE, Feller AC, Pauli M, et al.: Contemporary classification of histiocytic disorders. The WHO committee on histiocytic/reticulum cell proliferations. Reclassification working group of the histiocyte society. Med Pediatr Oncol 1997; 29: 157-66.

8. Yousem SA, Dacic S, Nikiforov YE, Nikiforova M: Pulmonary Langerhans cell histiocytosis: profiling of multifocal tumors using nextgeneration sequencing identifies concordant occurrence of BRAF V600E mutations. Chest 2013; 143: 1679-84.

9. Lazor R, Etienne-Mastroianni B, Khouatra C, Tazi A, Cottin V, Cordier JF: Progressive diffuse pulmonary Langerhans cell histiocytosis improved by cladribine chemotherapy. Thorax 2009; 64: 274-5.

10. Haroche J, Cohen-Aubart F, Emile JF, et al.: Dramatic efficacy of vemurafenib in both multisystemic and refractory Erdheim-Chester disease and Langerhans cell histiocytosis harboring the BRAF V600E mutation. Blood 2013; 121: 1495-500.

11. Myers JL, Veal CF, Shin MS, Katzenstein AL: Respiratory bronchiolitis causing interstitial lung disease. A clinicopathologic study of six cases. Am Rev Respir Dis 1987; 135: 880-4.

12. Carrington CB, Gaensler EA, Coutu RE, FitzGerald MX, Gupta RG: Natural history and treated course of usual and desquamative interstitial pneumonia. N Engl J Med 1978; 298: 801-9.

13. Yousem SA, Colby TV, Gaensler EA: Respiratory bronchiolitisassociated interstitial lung disease and its relationship to desquamative interstitial pneumonia. Mayo Clin Proc 1989; 64: 1373-80.

14. Verleden GM, Sels F, van Raemdonck D, Verbeken EK, Lerut T, Demedts $\mathrm{M}$ : Possible recurrence of desquamative interstitial pneumonitis in a single lung transplant recipient. Eur Respir J 1998; 11: 971-4.

15. Hubbard R, Lewis S, Richards K, Johnston I, Britton J: Occupational exposure to metal or wood dust and aetiology of cryptogenic fibrosing alveolitis. Lancet 1996; 347: 284-9.

16. Baumgartner KB, Samet JM, Stidley CA, Colby TV, Waldron JA: Cigarette smoking: a risk factor for idiopathic pulmonary fibrosis. Am J Respir Crit Care Med 1997; 155: 242-8.

17. Behr J, Gunther A, Ammenwerth W, et al.: German guideline for diagnosis and management of idiopathic pulmonary fibrosis. Pneumologie 2013; 67: 81-111.

18. Raghu G, Collard HR, Egan JJ, et al.: An official ATS/ERS/JRS/ALAT statement: idiopathic pulmonary fibrosis: evidence-based guidelines for diagnosis and management. Am J Respir Crit Care Med 2011; 183: 788-824.

19. Ley B, Ryerson CJ, Vittinghoff E, et al.: A multidimensional index and staging system for idiopathic pulmonary fibrosis. Ann Intern Med 2012; 156: 684-91

20. Demedts M, Behr J, Buhl R, et al.: High-dose acetylcysteine in idiopathic pulmonary fibrosis. N Engl J Med 2005; 353: 2229-42.

21. Idiopathic Pulmonary Fibrosis Clinical Research Network, Martinez FJ, de Andrade JA, Anstrom KJ, King TE, Raghu G: Randomized trial of acetylcysteine in idiopathic pulmonary fibrosis. N Engl J Med 2014; 370: 2093-101.

22. Noble PW, Albera C, Bradford WZ, et al.: Pirfenidone in patients with idiopathic pulmonary fibrosis (capacity): two randomised trials. Lancet 2011; 377: 1760-9.

23. King TE, Bradford WZ, Castro-Bernardini S, et al.: A phase 3 trial of pirfenidone in patients with idiopathic pulmonary fibrosis. $\mathrm{N}$ Engl $\mathrm{J}$ Med 2014; 370: 2083-92.

24. Richeldi L, du Bois RM, Raghu G, et al.: Efficacy and safety of nintedanib in idiopathic pulmonary fibrosis. N Engl J Med 2014; 370: 2071-82.

25. Song JW, Hong SB, Lim CM, Koh Y, Kim DS: Acute exacerbation of idiopathic pulmonary fibrosis: incidence, risk factors and outcome. Eur Respir J 2011; 37: 356-63. 
26. Ozawa Y, Suda T, Naito T, et al.: Cumulative incidence of and predictive factors for lung cancer in IPF. Respirology 2009; 14 723-8.

27. Lee JS, Collard HR, Anstrom KJ, et al.: Anti-acid treatment and disease progression in idiopathic pulmonary fibrosis: an analysis of data from three randomised controlled trials. Lancet Respir Med 2013; 1: 369-76.

28. Cottin V, Nunes H, Brillet PY, et al.: Combined pulmonary fibrosis and emphysema: a distinct underrecognised entity. Eur Respir J 2005; 26: 586-93.

29. Jankowich MD, Rounds SI: Combined pulmonary fibrosis and emphysema syndrome: a review. Chest 2012; 141: 222-31.

30. Rhee CK, Min KH, Yim NY, et al.: Clinical characteristics and corticosteroid treatment of acute eosinophilic pneumonia. Eur Respir $\mathrm{J}$ 2013; 41: 402-9.

31. Shorr AF, Scoville SL, Cersovsky SB, et al.: Acute eosinophilic pneumonia among US Military personnel deployed in or near Iraq. JAMA 2004; 292: 2997-3005

32. Kelly CA, Saravanan V, Nisar M, et al.: Rheumatoid arthritis-related interstitial lung disease: associations, prognostic factors and physiological and radiological characteristics-a large multicentre UK study. Rheumatology (Oxford) 2014; 53: 1676-82.

33. Chan AL, Louie S, Leslie KO, Juarez MM, Albertson TE: Cutting edge issues in Goodpasture's disease. Clin Rev Allergy Immunol 2011; 41: 151-62.

34. Inoue Y, Trapnell BC, Tazawa R, et al.: Characteristics of a large cohort of patients with autoimmune pulmonary alveolar proteinosis in Japan. Am J Respir Crit Care Med 2008; 177: 752-62.
35. Tazawa R, Trapnell BC, Inoue Y, et al.: Inhaled granulocyte/macrophagecolony stimulating factor as therapy for pulmonary alveolar proteinosis. Am J Respir Crit Care Med 2010; 181: 1345-54.

36. Huppmann P, Sczepanski B, Boensch M, et al.: Effects of inpatient pulmonary rehabilitation in patients with interstitial lung disease. Eur Respir J 2013; 42: 444-53.

37. Magnussen H, Kirsten AM, Kohler D, et al.: Guidelines for long-term oxygen therapy. German Society for Pneumology and Respiratory Medicine. Pneumologie 2008; 62: 748-56.

38. Orens JB, Estenne M, Arcasoy S, et al.: International guidelines for the selection of lung transplant candidates: 2006 update - a consensus report from the Pulmonary Scientific Council of the International Society for Heart and Lung Transplantation. J Heart Lung Transplant 2006; 25: 745-55

39. Jankowich MD, Polsky M, Klein M, Rounds S: Heterogeneity in combined pulmonary fibrosis and emphysema. Respiration 2008; 75: 411-7.

\section{Corresponding author}

Dr. med. Lars Hagmeyer

Bethanien Krankenhaus Solingen

Aufderhöher Str. 169-75, 42699 Solingen, Germany

Lars.Hagmeyer@klinik-bethanien.de

Cor eReferences please refer to:

www.aerzteblatt-international.de/ref0415

eFigure:

www.aerzteblatt-international.de/15m0043 


\title{
Smoking-Related Interstitial Lung Disease
}

\author{
Lars Hagmeyer, Winfried Randerath
}

\section{eReferences}

e1. Wells AU, Nicholson AG, Hansell DM: Challenges in pulmonary fibrosis . 4: smoking-induced diffuse interstitial lung diseases. Thorax 2007; 62: 904-10.

e2. Bonella F, Bauer PC, Griese M, Ohshimo S, Guzman J, Costabel U: Pulmonary alveolar proteinosis: new insights from a single-center cohort of 70 patients. Respir Med 2011; 105: 1908-16.

e3. Schönfeld N, Dirks K, Costabel U, Loddenkemper R; Wissenschaftliche Arbeitsgemeinschaft für die Therapie von Lungenkrankheiten: A prospective clinical multicentre study on adult pulmonary Langerhans' cell histiocytosis. Sarcoidosis Vasc Diffuse Lung Dis 2012; 29: 132-8.

e4. Sholl LM, Hornick JL, Pinkus JL, Pinkus GS, Padera RF: Immunohistochemical analysis of langerin in langerhans cell histiocytosis and pulmonary inflammatory and infectious diseases. Am J Surg Pathol 2007; 31: 947-52.

e5. Mogulkoc N, Veral A, Bishop PW, Bayindir U, Pickering CA, Egan $\mathrm{JJ}$ : Pulmonary Langerhans' cell histiocytosis: radiologic resolution following smoking cessation. Chest 1999; 115: 1452-5.

e6. Fartoukh M, Humbert M, Capron F, et al.: Severe pulmonary hypertension in histiocytosis X. Am J Respir Crit Care Med 2000; 161: 216-23.

e7. Chaowalit N, Pellikka PA, Decker PA, et al.: Echocardiographic and clinical characteristics of pulmonary hypertension complicating pulmonary Langerhans cell histiocytosis. Mayo Clin Proc 2004; 79: 1269-75.

e8. Travis WD, Borok Z, Roum JH, et al.: Pulmonary Langerhans cell granulomatosis (histiocytosis X). A clinicopathologic study of 48 cases. Am J Surg Pathol 1993; 17: 971-86.

e9. Friedman PJ, Liebow AA, Sokoloff J: Eosinophilic granuloma of lung. Clinical aspects of primary histiocytosis in the adult. Medicine (Baltimore) 1981; 60: 385-96.

e10. Lorillon G, Bergeron A, Detourmignies L, et al.: Cladribine is effective against cystic pulmonary Langerhans cell histiocytosis. Am J Respir Crit Care Med 2012; 186: 930-2.

e11. Carson DA, Wasson DB, Taetle R, Yu A: Specific toxicity of 2-chlorodeoxyadenosine toward resting and proliferating human lymphocytes. Blood 1983; 62: 737-43.

e12. Dauriat G, Mal H, Thabut G, et al.: Lung transplantation for pulmonary langerhans' cell histiocytosis: a multicenter analysis. Transplantation 2006; 81: 746-50.

e13. Colby TV: Bronchiolitis. Pathologic considerations. Am J Clin Pathol 1998; 109: 101-9.

e14. Fraig M, Shreesha U, Savici D, Katzenstein AL: Respiratory bronchiolitis: a clinicopathologic study in current smokers, ex-smokers and never-smokers. Am J Surg Pathol 2002; 26: 647-53.

e15. Portnoy J, Veraldi KL, Schwarz MI, et al.: Respiratory bronchiolitisinterstitial lung disease: long-term outcome. Chest 2007; 131: 664-71.

e16. Bone RC, Wolfe J, Sobonya RE, et al.: Desquamative interstitial pneumonia following chronic nitrofurantoin therapy. Chest 1976; 69: 296-7.

e17. Corrin B, Price AB: Electron microscopic studies in desquamative interstitial pneumonia associated with asbestos. Thorax 1972; 27: $324-31$

e18. Lougheed MD, Roos JO, Waddell WR, Munt PW: Desquamative interstitial pneumonitis and diffuse alveolar damage in textile workers. Potential role of mycotoxins. Chest 1995; 108: 1196-200.

e19. Rawbone RG, Shaw MT, Jackson JG, Bagshawe KD: Complication of methotrexate-maintained remission in lymphoblastic leukemia. Br Med J 1971; 4: 467-8.

e20. Stillwell PC, Norris DG, O'Connell EJ, Rosenow EC, Weiland LH, Harrison EG: Desquamative interstitial pneumonitis in children. Chest 1980; 77: 165-71.

e21. Travis WD, Matsui K, Moss J, Ferrans VJ: Idiopathic nonspecific interstitial pneumonia: prognostic significance of cellular and fibrosing patterns: survival comparison with usual interstitial pneumonia and desquamative interstitial pneumonia. Am J Surg Pathol 2000; 24: 19-33.

e22. Flusser G, Gurman G, Zirkin H, Prinslo I, Heimer D: Desquamative interstitial pneumonitis causing acute respiratory failure, responsive only to immunosuppressants. Respiration 1991; 58: 324-6.

e23. Raghu G, Weycker D, Edelsberg J, Bradford WZ, Oster G: Incidence and prevalence of idiopathic pulmonary fibrosis. Am J Respir Crit Care Med 2006; 174: 810-6.

e24. Armanios MY, Chen JJ, Cogan JD, et al.: Telomerase mutations in families with idiopathic pulmonary fibrosis. N Engl J Med 2007; 356: 1317-26.

e25. Mushiroda T, Wattanapokayakit S, Takahashi A, et al.: A genomewide association study identifies an association of a common variant in TERT with susceptibility to idiopathic pulmonary fibrosis. J Med Genet 2008; 45: 654-6.

e26. www.clinicaltrials.gov, Stud-Ident-Nr: NCT01371305; NCT01629667; NCT01769196; NCT01890265; NCT01766817; NCT02036580; NCT01872689 (last accessed on 29 October 2014).

e27. Collard HR, Moore BB, Flaherty KR, et al.: Acute exacerbations of idiopathic pulmonary fibrosis. Am J Respir Crit Care Med 2007; 176: 636-43.

e28. Raghu G, Freudenberger TD, Yang S, et al.: High prevalence of abnormal acid gastro-oesophageal reflux in idiopathic pulmonary fibrosis. Eur Respir J 2006; 27: 136-42.

e29. Cottin V, Le Pavec J, Prevot G, et al.: Pulmonary hypertension in patients with combined pulmonary fibrosis and emphysema syndrome. Eur Respir J 2010; 35: 105-11.

e30. Jankowich MD, Rounds S: Combined pulmonary fibrosis and emphysema alters physiology but has similar mortality to pulmonary fibrosis without emphysema. Lung 2010; 188: 365-73.

e31. Ryerson CJ, Hartman T, Elicker BM, et al.: Clinical features and outcomes in combined pulmonary fibrosis and emphysema in idiopathic pulmonary fibrosis. Chest 2013; 144: 234-40.

e32. Mejia M, Carrillo G, Rojas-Serrano J, et al.: Idiopathic pulmonary fibrosis and emphysema: decreased survival associated with severe pulmonary arterial hypertension. Chest 2009; 136: 10-5.

e33. Sauvaget E, Dellamonica J, Arlaud K, et al.: Idiopathic acute eosinophilic pneumonia requiring ECMO in a teenager smoking tobacco and cannabis. Pediatr Pulmonol 2010; 45: 1246-9.

e34. Hutchinson D, Shepstone L, Moots R, Lear JT, Lynch MP: Heavy cigarette smoking is strongly associated with rheumatoid arthritis (RA), particularly in patients without a family history of RA. Ann Rheum Dis 2001; 60: 223-7.

e35. Cavagna L, Monti S, Grosso V, et al.: The multifaceted aspects of interstitial lung disease in rheumatoid arthritis. Biomed Res Int 2013; 2013: 759-60. 
e36. Vij R, Strek ME: Diagnosis and treatment of connective tissue disease-associated interstitial lung disease. Chest 2013; 143: 814-24.

e37. Dixon WG, Hyrich KL, Watson KD, et al.: Influence of anti-TNF therapy on mortality in patients with rheumatoid arthritisassociated interstitial lung disease: results from the British Society for Rheumatology Biologics Register. Ann Rheum Dis 2010; 69: 1086-91.

e38. Leatherman JW, Davies SF, Hoidal JR: Alveolar hemorrhage syndromes: diffuse microvascular lung hemorrhage in immune and idiopathic disorders. Medicine (Baltimore) 1984; 63: 343-61.

e39. Seymour JF, Presneill JJ: Pulmonary alveolar proteinosis: progress in the first 44 years. Am J Respir Crit Care Med 2002; 166: 215-35.

e40. Huizar I, Kavuru MS: Alveolar proteinosis syndrome: pathogenesis, diagnosis, and management. Curr Opin Pulm Med 2009; 15: 491-8.

e41. Holland AE, Hill CJ, Conron M, Munro P, McDonald CF: Short term improvement in exercise capacity and symptoms following exercise training in interstitial lung disease. Thorax 2008; 63: 549-54.

e42. Ferreira A, Garvey C, Connors GL, et al.: Pulmonary rehabilitation in interstitial lung disease: benefits and predictors of response. Chest 2009; 135: 442-7.

e43. Smits JM, Nossent GD, de Vries E, et al.: Evaluation of the lung allocation score in highly urgent and urgent lung transplant candidates in eurotransplant. J Heart Lung Transplant 2011; 30: 22-8. e44. Schonfeld N, Frank W, Wenig S, et al.: Clinical and radiologic features, lung function and therapeutic results in pulmonary histiocytosis X. Respiration 1993; 60: 38-44.

e45. Moon J, du Bois RM, Colby TV, Hansell DM, Nicholson AG: Clinical significance of respiratory bronchiolitis on open lung biopsy and its relationship to smoking related interstitial lung disease. Thorax 1999; 54: 1009-14.

e46. Tazi A, Soler P, Hance AJ: Adult pulmonary Langerhans' cell histiocytosis. Thorax 2000; 55: 405-16.

e47. Galvin JR, Franks TJ: Smoking-related lung disease. J Thorac Imaging 2009; 24: 274-84.

e48. Costabel U, Guzman J, Bonella F, Oshimo S: Bronchoalveolar lavage in other interstitial lung diseases. Semin Respir Crit Care Med 2007; 28: 514-24.

e49. Kawabata Y, Takemura T, Hebisawa A, et al.: Eosinophilia in bronchoalveolar lavage fluid and architectural destruction are features of desquamative interstitial pneumonia. Histopathology 2008; 52 194-202.

e50. Ryu JH, Colby TV, Hartman TE, Vassallo R: Smoking-related interstitial lung diseases: a concise review. Eur Respir J 2001; 17: 122-32.

e51. Liebow AA, Steer A, Billingsley JG: Desquamative Interstitial Pneumonia. Am J Med 1965; 39: 369-404.

e52. Colby TV, Swensen SJ: Anatomic distribution and histopathologic patterns in diffuse lung disease: correlation with HRCT. J Thorac Imaging 1996; 11: 1-26. 


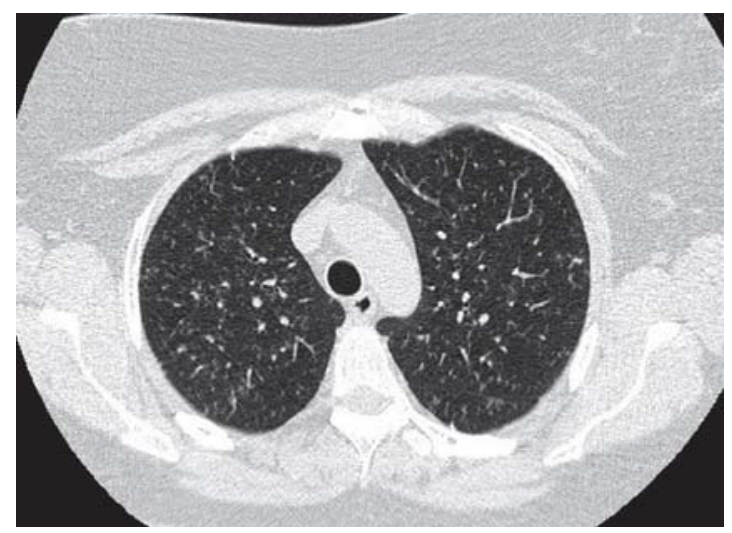

eFigure: High-resolution computer tomography in in pulmonary Langerhans cell histiocytosis (PLCH). Early stage with typical bronchiolocentric star-shaped nodules. 